\title{
ИНСТИТУЦИОНАЛЬНАЯ ОЦЕНКА МЕНЕДЖМЕНТА АКЦИОНЕРНОЙ КОМПАНИИ
}

\author{
(c) 2021 Попова Елена Александровна \\ доктор экономических наук, доцент \\ Южно-Уральский государственный университет \\ (Национальный Исследовательский Университет), Россия, Челябинск \\ E-mail:73519045153@yandex.ru \\ (c) 2021 Демина Надежда Константиновна \\ кандидат экономических наук \\ Южно-Уральский государственный университет \\ (Национальный Исследовательский Университет), Россия, Челябинск \\ E-mail:deminank@susu.ru \\ (c) 2021 Базелюк Владимир Васильевич \\ доктор педагогических наук \\ Южно-Уральский государственный университет \\ (Национальный Исследовательский Университет), Россия, Челябинск \\ E-mail: bazeliukvv@susu.ru \\ (c) 2021 Елисеев Алексей Викторович \\ кандидат экономических наук \\ Южно-Уральский государственный университет \\ (Национальный Исследовательский Университет), Россия, Челябинск \\ E-mail: eliseevav@susu.ru
}

Актуализирована проблема институциональной оценки системы управления предприятием, функционирующим в форме акционерного общества. С позиций методологического анализа представлен механизм такой оценки. Осуществлено обоснование необходимости институциональной оценки деятельности по принятию управленческих решений в публичных корпорациях

Ключевые слова: институциональная экономика, менеджмен, акционерное общество, управленческий труд, институциональный механизм.

Введение. В управлении объектами как на микро-, так и на макроуровне мониторинг достижения целей, оценивание результатов реализации проектов является важным элементом управленческой деятельности. В ходе сбора статистических данных по оценке различных аспектов функционирования организаций вносятся коррективы в методологию оценочной деятельности. Особенностями объектов управления в современном мире является их динамический характер, т.е. изменяемость с течением времени, поэтому механизм мониторинга состояния объекта должен иметь непрерывный характер, такая ситуация формирует необходимость автоматизации процесса сбора данных [5].

Экономическая наука включает в себя изучение управления таким сложным объектом как акционерная компания, одним из важнейших вопросов является механизм влияния акционеров на действия менеджмента корпорации. В рамках теории институционализма менеджеры акционерной компании являются принципалами по отношению к рядовым работникам и (одновременно) агентами по отношению к акционерам. Говоря иначе, менеджеры являются как субъектом, так и предметом оценивания своеобразного «экономического блага».

Нами в данной работе акцентируется внимание на всем этом, а также на том, что именно институциональная оценка системы менеджмента акционерного предприятия является наиболее важной и ценной с позиций ее объективности и целесообразности. Благодаря ее наличию проблема оценки обнаруживает более глубокое ее понимание как с позиций теории, так и практики предпринимательской деятельности на 
уровне акционерного предприятия. Это тем более важно, что именно данный хозяйствующий субъект сам относится к числу институтов, то есть определенной совокупности рамок, структурирующих определенные взаимодействия и требующих процессов оценки действий в рамках системы корпоративного менеджмента.

Степень исследованности. В самом общем виде данная работа посвящена оценке управленческого труда, играющего важную (определяющую) роль жизнедеятельности любого хозяйствующего субъекта. Это означает, что аналитикам следует оперировать с определенным набором количественных и качественных показателей осуществления управленческих функций, отражающих соответствие результатов определенному «оптимуму» [6]. Интерес в этом плане представляют труды отечественных ученых-экономистов (И.К.Быстряков, Е.В.Глущенко, Е.В.Захаров, Ю.Р. Лутфуллин, А.М.Масс, Г.Н.Пряхин, О.М.Рой, Ю.В.Тихонравов, В.Ф.Уколов и др.). Интерес представляют также работы зарубежных авторов. В их числе - М. Вебер, Э. Мэто, Т. Питерс, У. Тейлор, Р. Уотермен [2].

Нами в работе акцент делается на институциональную оценку менеджеров акционерного предприятия. Она - в определенном плане - является обобщающей, затрагивающей не только внутреннюю, но и внешнюю сторону деятельности данного хозяйствующего субъекта. Ее целевой установкой является поиск наиболее эффективных и действенных механизмов поддержания целостности данного субъекта институциональных отношений современного предпринимательства (его управляемости с по- зиций эволюции самоорганизующихся систем менеджмента). При этом, как показано в работе, важным является вопрос о выработке общих закономерностей данной оценки институциональной направленности.

Результаты исследования. Алгоритмически они представлены в виде схемы на рисунке 1. На нем выделены три институциональные оценки менеджмента акционерного предприятия.

1. Первая из них имеет особое значение в силу значимости работы менеджеров в сфере достижения запланированного результата (поставленной заранее цели предпринимательской деятельности, осуществляемой акционерным предприятием). Методы оценки следующие:

- рейтинг (это метод оценки личных качеств - внимательность, честность, доступность, авторитетность, вдумчивость, тактичность, коммуникабельность и др.);

- интервью (учитываются следующие личностные компоненты: отношение к работе, интеллект, мотивация, характер, темперамент, здоровье и др.);

- метод комитетов (оценка группой экспертов менеджера, выдвигаемого на более высокую должность). Управленческая деятельность разбивается на отдельные составляющие, определяя при этом результативность каждой из них по десятибалльной системе. Далее составляется перечень работ, которые удается решать успешно в рамках конкретной производственнокоммерческой или финансовой деятельности.

Известны также методы независимых судей и оценочных центров. В их центре лежат действия менеджеров, связанные с разработкой

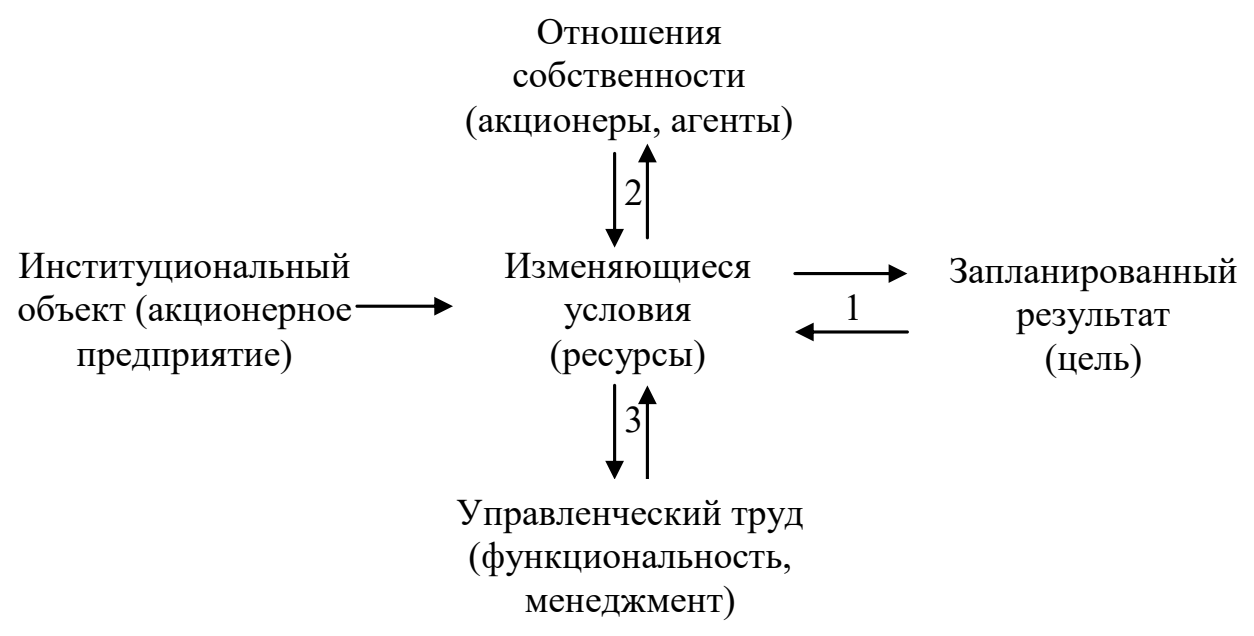

Рисунок 1. Структурная схема функционирования акционерного предприятия: $1,2,3$ - подходы к институциональной оценке менеджмента 
проектов, принятием решений, выполнением иных управленческих действий.

В целом система менеджмента акционерного предприятия оценивается конкретными показателями эффективности и действенности [3]. Последние определяются достижением поставленных агентским центром целей и ролью в этом конкретных менеджеров.

2. Институциональная оценка менеджмента акционерного предприятия с позиций агентской проблемы. Прежде всего, это система корпоративного управления с конкретными внешними инструментами, а именно: институт несостоятельности (банкротства), рынок ценных бумаг, рынок корпоративного контроля, рынок менеджеров (неудачи предприятия лишают некоторых из них работы и ухудшают репутацию, конкурентоспособность).

Назовем далее некоторые механизмы корпоративного правления [4]. Имеется в виду: деятельность собрания акционеров (принимаемые ими решения); контроль Совета директоров за текущей деятельностью исполнительного менеджмента акционерного предприятия; стимулирующие контракты менеджеров. В качестве целевых индикаторов в последнем случае выступает прибыль, выручка, успешная реализация инвестиционного (инновационного) проекта, рыночная цена акционерного предприятия (ее рост за конкретный промежуток времени).

С позиций агентской проблемы менеджмент акционерного предприятия следует рассматривать с двух позиций: менеджеры (принципалы) - работники (агенты); менеджеры (агенты) - акционеры (принципалы).

Первая позиция определяется наличием проблемы, в соответствии с которой важен контроль над действиями работников, которые существенную часть своего времени думают о том, как медленно можно работать при получении той же зарплаты (Ф.Тейлор). Ее решение в рамках институциональной экономики связано моделированием внутренней структуры акционерного предприятия.

Одна из этих структур унитарная, связанная с прямым контролем над действиями агентов. Другая структура - холдинговая, определяемая соревнованиями агентов, а третья - дивизионная. Ее основа - участие агентов в прибылях данного хозяйствующего субъекта. Это так называемая децентрализованная структура.

Особую роль в рамках данной структуры играет деловая культура работников (и самих менеджеров), а также организационная культура. Роль последней определяется интегративной функцией, в соответствии с которой агентам дается возможность институциональной оценки действий менеджеров в разных производственных ситуациях. Говоря иначе, речь идет об идентичности отношений в случае их отклонений от норм организационной культуры.

Особую роль в рамках рассматриваемого вопроса играет так называемая «рутина», суть которой заключается в запоминании действий через их регулярное повторение и обеспечении информационного обмена между членами акционерного предприятия. С позиций институциональной экономики речь идет о новых формах поведения (стабильности) и институтах (структуры хозяйствующего субъекта).

Стоит обратить внимание на «издержки рутинизации». Именно благодаря им осуществляется решение проблемы принципала и агента (через снижение информационной асимметрии внутри хозяйствующего субъекта).

Перейдем далее к проблемной позиции «менеджер (агент) - акционеры (принципалы)». Она решается или «голосом» (участии акционеров в годовых собраниях), или «выходом» (продаже акций, если менеджеры управляют предприятием не эффективно).

Такова одна из институциональных оценок менеджмента акционерного предприятия. Но есть и другие виды оценок, влияющих на деловой успех и конкурентоспособность любого хозяйствующего субъекта.

3. Функциональный подход к институциональной оценке менеджмента акционерного предприятия. Примером здесь является принятие управленческого решения (его качество и эффективность). Об этом можно судить по схеме, представленной на рисунке 2. Не нем показаны два кругооборота, объединенные блоками: информация о желаемом и действительном состоянии (в рамках наличия конкретной проблемы) и разработка и принятие управленческого решения. На схеме представлены еще два блока. Это целевые установки акционерного предприятия и реализация управленческого решения, направленного на решение проблемы (реальной или возможной в перспективе в условиях конкуренции на рынке производимых товаров или услуг).

Принятие управленческих решений можно 


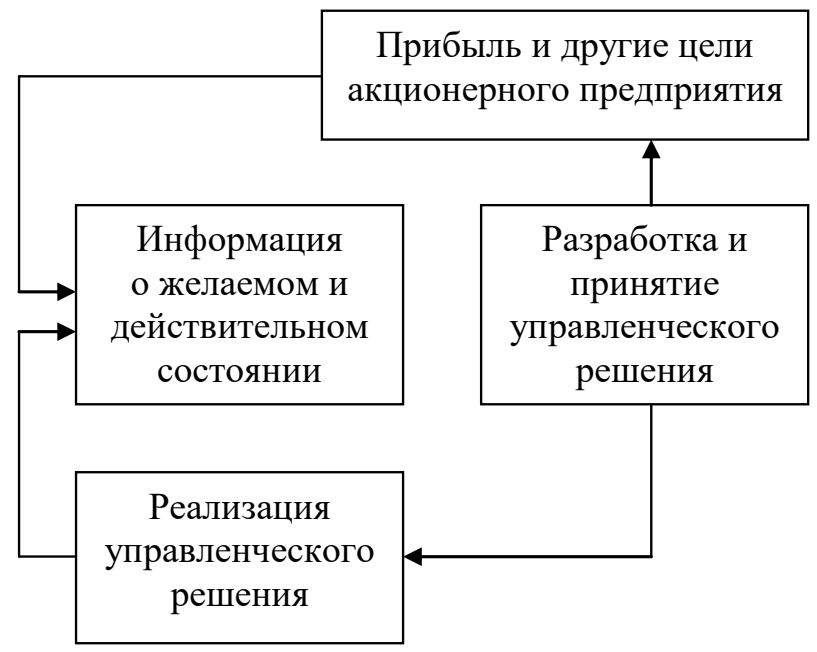

Рисунок 2. Менеджерская деятельность по принятию управленческих решений

представить в виде функций, определяющих суть управленческого труда в рамках системы корпоративного менеджмента акционерного предприятия. Речь идет о функциональном поле данных решений, контролируемом данной системой (рисунок 3).

Функциональное поле всегда находится в центре внимания специалистов, в том числе и руководителей того или иного акционерного предприятия. С позиций институциональной экономики это поле имеет четыре сегмента, один из которых определяется функциями целевого управления. В процессе исследования нами акцент делается на анализе организационных структур. Имеется в виду: 1) сравнительный ана- лиз организационных издержек; 2) баланс акционерного предприятия как источник информации о его структуре; 3) анализ и разрешение внутриорганизационных конфликтов на основе теории соглашений; 4) анализ организационноправовой формы акционерного предприятия. Данный вид анализа имеет непосредственное отношение к оценке оптимальности различных конфигураций прав собственности. Немаловажную роль при этом играют варианты решения проблем принципалов и агентов.

Функциональное поле принятия управленческих решений включает в свой состав не только описанные ранее функции целевого управления, но также обеспечивающие и операционные

\begin{tabular}{|l|l|}
\hline $\begin{array}{l}\text { Функции } \\
\text { уелевог } \\
\text { управления }\end{array}$ & $\begin{array}{l}\text { Анализ } \\
\text { Учет } \\
\text { Принятие } \\
\text { Проектирование }\end{array}$ \\
\hline $\begin{array}{l}\text { Обеспечивающие } \\
\text { функции } \\
\text { управления }\end{array}$ & $\begin{array}{l}\text { Финансирование } \\
\text { Экономическая безопасность } \\
\text { Технологизация } \\
\text { Организационное культуростроение }\end{array}$ \\
\hline $\begin{array}{l}\text { Функции } \\
\text { реального } \\
\text { управления }\end{array}$ & $\begin{array}{l}\text { Планирование } \\
\text { Контроль } \\
\text { Регулирование } \\
\text { Мотивация }\end{array}$ \\
\hline $\begin{array}{l}\text { Операционные } \\
\text { функции } \\
\text { предприятия }\end{array}$ & $\begin{array}{l}\text { Производство } \\
\text { Маркетинг } \\
\text { Снабжение } \\
\text { Организация }\end{array}$ \\
\hline
\end{tabular}

Рисунок 3. Функциональное поле принятия решений в системе корпоративного менеджмента 
функции, а также (как это следует из рисунка 3) функции реального управления. Все они - в явном или неявном виде - имеют отношение к «экономизации» процесса разработки управленческого решения менеджерами акционерного предприятия.

Необходимость анализа процесса разработки управленческого решения в координатах экономизации обеспечивается, на наш взгляд, следующим. Во-первых, предмет исследования (как и сама проблема) является многоаспектным (с позиций учета философской, социальной, психологической и экономической подготовки лиц, разрабатывающих и применяющих управленческие решения). Во-вторых, проблема нашего исследования является методологической. И, в-третьих, приступая к анализу исследуемой проблемы, мы неизбежно сталкиваемся с необходимостью выделения руководящих идей, принципов, условий, методов ее изучения и решений в педагогическом аспекте.

Таким образом, исходным действием нашего исследования является определение его познавательной и методологической базы (и уже далее следует выполнение анализа проблемы и разработка на этой основе методических (практических) положений экономизации процесса разработки управленческого решения в системе спортивного менеджмента).

Экономизация - не единственный принцип разработки управленческих решений, особенно если они принимаются в условиях риска и неопределенности. К числу других принципов следует отнести: анализ хода собственных мыслей, логичность и последовательность рассуждений, реалистичность оценки условий и трудностей, гибкость и учет мнений специалистов (исходя из функционального подхода). Это также принцип, в соответствии с которым следует остерегаться «минных полей», то есть сложных участков, где могут быть опасности [1]. Особую роль при этом играет институциональный образ мышления лица, принимающего управленческие решения (и прежде всего топ-менеджера акционерного предприятия).

В качестве обобщения отметим, что любая оценка трудовой деятельности менеджеров слу- жит трем целям: информационной, мотивационной, административной [7]. Последняя возникает как реакция на результат такой оценки.

Оценка включает в себя использование разных методов получения информации, сравнение оцениваемого явления с практическими результатами (информацией). При этом следует различать субъект, объект и предмет оценки, а также (как уже отмечалось) процедура получения оценки [1].

Кроме того, институциональная оценка предусматривает следующие критерии сравнения: характер санкций за невыполнение конкретных предписаний; правила, нормы, стратегические установки; учет наличия трансакционных издержек; направленность осуществляемых действий.

\section{Заключение.}

1. Институциональная оценка менеджмента акционерного предприятия имеет определенную направленность. Как показано в работе, это: оценка по целям и результатам предпринимательской деятельности; оценка менеджерской деятельности с позиций агентской проблемы; функциональный подход к оценке эффективности и действенности принимаемых решений.

2. С позиций институциональной экономической теории оценка менеджмента связана с решением определенных проблем. K числу важнейших из них авторы относят эффективное разделение труда и выбор способов его стимулирования. Это также оптимизация в сфере разграничения полномочий между уровнями управления, подбор адекватных методов управленческого воздействия на хозяйственную деятельность акционерного предприятия и выработка целостного взгляда на природу управления (управленческую деятельность).

3. Все критерии оценки менеджмента акционерного предприятия следует определенным образом классифицировать по степени операционализации, ответственности, публичности (с позиций контактов с персоналом). Их можно также подразделить по характеру оценки, которая может носить не только деловой, но также этический и психологический характер. 


\section{Библиографический список}

1. Виноградова, Н.П. Микроэкономика / Н.П.Виноградова, А.Н.Попов, А.А.Попова.- Костанай: Костанайский филиал ЧелГУ, 2016.- 238 с.

2. Питерс, Т. В поисках эффективного управления: опыт лучших компаний. Пер. с англ. / Т. Питерс, Р. Уотермен.-М.: Прогресс, 1986.-268 с.

3. Попов, А.Н.Институциональная экономика / А. Н.Попов, Н. В. Ксенафонтов.- Екатеринбург: УрГЭУ, 2004.$60 \mathrm{c}$.

4. Попов, А.Н.Корпоративный менеджмент в координатах делового успеха / А.Н.Попов.- Магнитогорск: МГТУ, 2016.- 234 с.

5. Ливщиц, К.И. Теория управления: учебник / К.И.Лившиц, Ю.И.Параев.-Санкт-Петербург: Лань, 2020.232 c.

6. Теория управления / В. Ф.Уколов и др.- М.: Экономика, 2004. - 656 с.

7. Управленческая экономика. Институциональные системы. Инструментарий для принятия управленческих решений / Н. П. Виноградова, А.Н. Попов.- Костанай: Костанайский филиал ЧелГУ, 2014. - 200 с. 